\title{
Omega-3 Polyunsaturated Fatty Acids in Prevention of Mood and Anxiety Disorders
}

\author{
Kuan-Pin Su ${ }^{1,2}$, Yutaka Matsuoka ${ }^{3}$, Chi-Un Pae ${ }^{4}$ \\ 'Department of Psychiatry and Mind-Body Interface Laboratory (MBI-Lab), China Medical University Hospital, ${ }^{2}$ Graduate Institute of Neural \\ and Cognitive Sciences, China Medical University, Taichung, Taiwan, ${ }^{3}$ Department of Clinical Epidemiology, Translational Medical Center, \\ National Center of Neurology and Psychiatry, Tokyo, Japan, ${ }^{4}$ Department of Psychiatry, College of Medicine, The Catholic University of \\ Korea, Seoul, Korea
}

\begin{abstract}
Psychiatric disorders in general, and major depression and anxiety disorders in particular, account for a large burden of disability, morbidity and premature mortality worldwide. Omega-3 polyunsaturated fatty acids (PUFAs) have a range of neurobiological activities in modulation of neurotransmitters, anti-inflammation, anti-oxidation and neuroplasticity, which could contribute to psychotropic effects. Here we reviewed recent research on the benefits of omega-3 PUFA supplements in prevention against major depression, bipolar disorders, interferon- $\alpha$-induced depression patients with chronic hepatitis $\mathrm{C}$ viral infection, and posttraumatic stress disorder. The biological mechanisms underlying omega-3 PUFAs' psychotropic effects are proposed and reviewed. Nutrition is a modifiable environmental factor that might be important in prevention medicine, which have been applied for many years in the secondary prevention of heart disease with omega-3 PUFAs. This review extends the notion that nutrition in psychiatry is a modifiable environmental factor and calls for more researches on prospective clinical studies to justify the preventive application of omega-3 PUFAs in daily practice.
\end{abstract}

KEY WORDS: Omega-3 (N-3) polyunsaturated fatty acids (PUFA); Depression; Anxiety disorders; Psychotic disorders; Clinical trials.

\section{INTRODUCTION}

Psychiatric disorders remain the leading cause of morbidity and mortality, accounting for $37 \%$ of healthy life years lost globally and five of the top ten causes of Disability Adjusted Life Years (DALY) ${ }^{1)}$ Furthermore, a considerable proportion of people with mental health problems remain untreated. For example, in the USA 67\% and in Europe $74 \%$ of people with mental illness are untreated. ${ }^{2)}$ Due to stigmatization and cultural differences, the situation is even worse in Asian countries. ${ }^{3)}$

Rapid urbanization and an overall transition from traditional lifestyles have been linked to increases in both physiological and mental illness. ${ }^{4}$ Although the psychophysiological responses to environment determinants of urbanization and modernization are complex, the emerg-

\footnotetext{
Received: January 20, 2015 / Revised: February 21, 2015

Accepted: February 22, 2015

Address for correspondence: Kuan-Pin Su, MD, PhD

Department of Psychiatry, China Medical University Hospital, No. 2, Yuh-Der Road, Taichung 404, Taiwan

Tel: +886-4-2206-2121, Fax: +886-4-2236-1230

E-mail: cobolsu@gmail.com
}

ing evidence suggests that nutrition is a critical factor for the increasing prevalence and incidence in psychiatric disorders. ${ }^{5)}$ For example, epidemiological, biological and clinical studies implicate that omega-3 fatty acids are important in the development and treatment of various mental illness, including mood and anxiety disorders. ${ }^{6-17)}$

Omega-3 polyunsaturated fatty acids (PUFAs) (also known as n-3 fatty acids or "fish oil") are essential macronutrients and must be obtained from dietary sources because the body cannot synthesize them effectively. ${ }^{18)}$ The major types of omega-3 PUFAs are eicosapentaenoic acid (EPA) and docosahexaenoic acid (DHA), and their precursor, alpha-linolenic acid (ALA). EPA and DHA are found primarily in fatty fish, such as salmon, and in fish-oil supplements. Sources of ALA include flax seed, canola, soybean, walnuts, and leafy green vegetables. Fish-oil supplements are among the most widely used dietary supplements. ${ }^{19)}$ Omega-3 PUFAs may provide a range of neurobiological activities via modulation of neurotransmitters, anti-inflammation, anti-oxidation and neuroplasticity, ${ }^{14,16,20,21)}$ which could contribute to their psychotropic effects.

(c) This is an Open-Access article distributed under the terms of the Creative Commons Attribution Non-Commercial License (http://creativecommons.org/licenses/by-nc/4.0) which permits unrestricted non-commercial use, distribution, and reproduction in any medium, provided the original work is properly cited. 
Early intervention and primary prevention is considered as the best strategies for the crisis of under-treatment and under-effectiveness because a majority of patients refuse to take medications due to adverse effects and/or stigmatization. In fact, some researchers are now proposing that high-risk populations could be helped much sooner, by being alert to signs that unfold during months or even years preceding onset of diseases. ${ }^{22)}$ Nutrition is a modifiable environmental factor that might be important in prevention medicine. For example, the use of omega-3 PUFAs in the secondary prevention of heart disease has been endorsed by the American Heart Association since $2002 .^{23)}$ This article reviews recent research on the benefits of omega-3 PUFA supplements in prevention of psychiatric disorders.

\section{MAIN SUBJECTS}

\section{Omega-3 PUFAs in Depression and Bipolar Disorders}

Psychiatric disorders based on current diagnostic systems are clinically and biologically heterogeneous. The heterogeneity is also reflected by current classification systems for antidepressant drugs (Fig. 1). For example, if the classification is based on serotonin reuptake, the agents with conflicting effects, such as the selective sero-

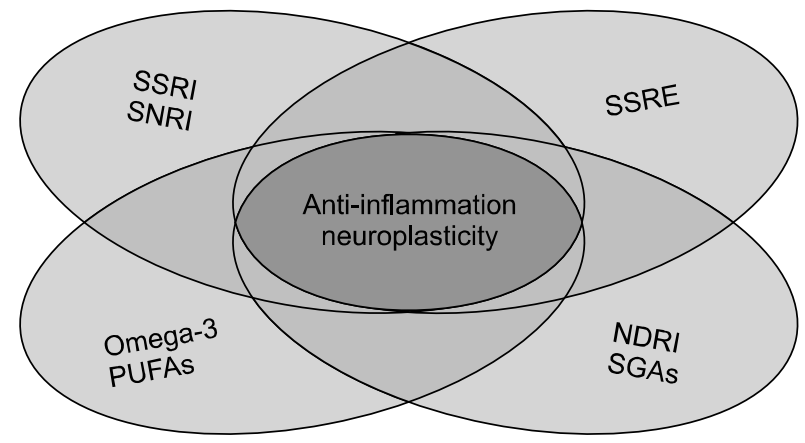

Fig. 1. Omega-3 polyunsaturated fatty acids (PUFAs) share the common biological mechanisms of anti-inflammation and neuroplasticity with current antidepressant agents. The heterogeneity of depression could be reflected by the limits of pharmacotherapy and pharmacological classification based on serotonin, norepinephrine and dopamine. Controversially, the agents that inhibit (i.e., SSRI \& SNRI), enhance (i.e., SSRE), or even neglect (i.e., NDRI \& SGAs) the serotonin reuptake action could all be approved to be antidepressant treatments, which seem to share common mechanisms of anti-inflammation and neuroplasticity. Interestingly, these two biological mechanisms are applicable not only for antidepressant agents from different categories but also for omega-3 PUFAs.

SSRI, selective serotonin reuptake inhibitor; SNRI, serotonin-norepinephrine reuptake inhibitors; SSRE, selective serotonin reuptake enhancer; NDRI, norepinephrine-dopamine reuptake inhibitor; SGA, second generation antipsychotic. tonin reuptake inhibitors (SSRI; e.g., fluoxetine or venlafaxine) and enhancers (SSRE; e.g., tianeptine) or the norepinephrine-dopamine reuptake inhibitors (NDRIs; e.g., bupropion), could all work as antidepressants. Interestingly, two common pathways, neuroprotection and anti-inflammation, have been found to be associated with all the antidepressant drugs. ${ }^{21,24)}$ More importantly, these two common mechanisms link to antidepressant effects not only for drugs but also for non-pharmacological treatment omega-3 PUFAs. ${ }^{6,11,20)}$ Indeed, the effects on neuroprotection and anti-inflammation support the promising hypothesis of psychoneuroimmunology of mood and anxiety disorders and provide an excellent interface between "mind" and "body".

The PUFAs hypothesis is enlightening a promising path to discover, at least partially, the unsolved of depression. Firstly, it has been observed that countries with a high consumption of fish diet appear to have a lower prevalence of major depressive disorder (MDD) ${ }^{25,26)}$ and bipolar disorders (BD), ${ }^{27)}$ implying a preventive effect of omega-3 PUFA on mood disorders. Secondly, patients with MDD have lower levels of n-3 PUFAs in tissues of blood ${ }^{14)}$ and brain. ${ }^{28-30)}$ In our recent meta-analytic review including 3,318 subjects, ${ }^{14)}$ the results further support omega-3 fatty acid deficits in MDD by showing a significant decrease in the levels of EPA (effect size $[\mathrm{ES}]=-0.18$, $p=0.004)$, DHA $(\mathrm{ES}=-0.35, p=0.0002)$ and total $\mathrm{n}-3$ PUFA (ES $=-0.51, p<0.0001)$.

The deficits in omega-3 PUFA levels have been reported in other populations with mood disorders, including lower DHA and total n-3 PUFAs in postpartum depression ${ }^{31)}$ and lower DHA and EPA in social anxiety disorder. ${ }^{32)}$ In the elderly patients, lower DHA and higher AA, n-6/n-3, AA/EPA, and AA/DHA ratios were associated with depressive disorders compared to healthy volunteers. ${ }^{33)}$ In samples of patients with acute coronary syndromes, the depressed patients had lower DHA, total DHA and EPA; and higher AA, n-6/n-3, AA/EPA and AA/DHA than those without depression. ${ }^{34)}$ Interestingly, lower DHA levels before starting interferon (IFN)- $\alpha$ therapy predicted IFN- $\alpha$-induced depression in patients with chronic hepatitis $\mathrm{C}$ viral (HCV) infection. ${ }^{13)}$

Six case-control studies have shown lower omega-3 PUFA status in erythrocyte membranes or plasma in patients with BD. Compared to healthy controls, significantly decreased DHA levels have been described in both manic patients under treatment ${ }^{35)}$ and in medication-free patients. $^{36)}$ Moreover, Ranjekar et al. $^{37)}$ found significantly decreased omega-3 ALA and EPA levels in eryth- 
rocyte of $\mathrm{BD}$ patients compared to age-matched healthy controls. Manic symptom severity was negatively correlated with plasma levels of EPA and AA. ${ }^{38)}$ Clayton et al. ${ }^{39)}$ have reported that erythrocyte DHA levels were negatively correlated with depressive symptoms in children and adolescents with BD. However, the findings could not be replicated in a recent study about the correlation between the severity of affective symptoms and omega-3 PUFA status in medication-free BD patients. ${ }^{36)}$ Interestingly, healthy first-degree relatives of BD patients had also a trend towards decreased blood omega-3 PUFA levels. ${ }^{40)}$

Omega-3 PUFAs have been reported to be effective in the treatment of BDs. In a pioneer randomized-controlled trial, omega-3 PUFAs showed prophylactic effects in the 4-month course of BD, with longer periods of clinical remission as compared to placebo. ${ }^{41)}$ The prophylactic effects seen in this study suggest antidepressant effects. Specifically, in our re-examination of the data reported by Stoll et al., ${ }^{41)}$ we found that all "non-completed (recurrent)" cases ( 3 out of 14 cases) in the omega-3 group developed manic episodes, whereas the depressive symptoms in all but 1 of the non-completed cases (10 out of 16 cases), in the placebo group worsened. This observation suggests that omega-3 PUFAs could prevent depression but not mania in patients with BD. ${ }^{42)}$ Till now, some clinical trials have been reported to support the antidepressant effect of omega-3 PUFAs on bipolar depression, ${ }^{43-46)}$ but the results are not all consistent. ${ }^{47-49)}$

Several independent groups reported meta-analytic reviews $^{17,50-53)}$ and clinical trials ${ }^{15,45,54-60)}$ to support that omega-3 PUFAs were more effective than placebo, or as effective as conventional antidepressant medication fluoxetine, ${ }^{61)}$ in treating patients with MDD. However, three meta-analyses from the two groups did not support the omega-3 PUFAs' antidepressant effects when heterogeneous populations (e.g., community individuals with only non-clinical depressive symptoms) were included. ${ }^{62-64)}$ However, these studies need to read and interpreted with caution for several limitations, such as pooling heterogeneous populations, using self-rating scales rather than structured interviews for clinical diagnosis, and implementing different intervention methods. ${ }^{65)}$ Omega-3 PUFAs have antidepressant (statistical) effects in patients with the Diagnostic and Statistical Manual of Mental Disorders (DSM)-defined MDD but not "mood-improving" effects on symptomatic individuals in which the diagnosis was not confirmed. ${ }^{52,53)}$ Meta-analyses, just like randomized clinical trials, may be affected by potential biases in terms of selection of trials (or patients) for analysis. ${ }^{53}$
The beneficial effects of n-3 PUFA in depression are further supported in pre-clinical studies of animal and cellular models. N-3 PUFAs are associated with a preventive and reductive effects of depression-like behaviours in animal model in rats. ${ }^{66-69)}$ In addition, the level of brain DHA is negatively correlated to the immobility time and is positively correlated to the swimming time. ${ }^{67)}$ We proposed several biological mechanisms of the antidepressant effect of n-3 PUFAs in previous reviews, including: (1) neurotransmitter regulations, (2) anti-inflammation and anti-oxidation, and (3) neuroplasticity effects. ${ }^{6,18,20,21,70)}$

\section{Omega-3 PUFAs in Prevention of IFN-induced Depression}

Due to the heterogeneity of depression, half of patients with MDD fail to achieve remission with optimized medication treatment ${ }^{71)}$ and every antidepressant treatment is expected to have only modest effects. For example, the effect sizes of omega-3 PUFAs range from 0.17-0.23 in treating DSM-defined MDD patients. ${ }^{52,53)}$ However, the effect sizes of current standard antidepressant drugs are not much better. In an excellent meta-analytic review, the effect sizes are 0.11 for mild to moderate, 0.17 for severe, and 0.47 for very severe type of MDD. ${ }^{72)}$ As omega-3 PUFAs are safe and well accepted and the current antidepressant drugs have significant adverse effects, it is of great clinical important to identify patients to treat or high-risk subjects to prevent with this safe and yet effective natural component. There is one example to demonstrate the potential preventive effect of omega-3 PUFAs in specific high-risk population of major depression induced by IFN- $\alpha$ therapy. $^{73)}$

IFN- $\alpha$ is the standard therapy for HCV infection; however, its clinical impact is reduced by its common and severe neuropsychiatric adverse effects. For example, up to $30 \%$ of patients develop IFN- $\alpha$-induced major depression. ${ }^{13)}$ Finding the best strategy to prevent IFN- $\alpha$-induced depression will improve clinical outcome, but previous clinical trials with SSRIs have had mixed results. ${ }^{73)}$ In addition, SSRI-induced gastrointestinal bleeding is concerned in $\mathrm{HCV}$ patients, ${ }^{74)}$ who may already have esophageal varices, cirrhosis, low platelet count, and tendency toward bleeding. ${ }^{75)}$ Furthermore, the use of antidepressants in patients receiving IFN- $\alpha$ therapy has been associated with rare but severe adverse effects, including retinal haemorrhaging and cotton-wool spots, ${ }^{76,77)}$ bone marrow suppression, hepatotoxicity, ${ }^{78,79)}$ and manic episodes. ${ }^{79)}$ As most patients receiving IFN- $\alpha$ do not develop clinically significant depression, the routine pre-treatment with anti- 
depressant drugs might expose patients to unnecessary medications. More importantly, we have previously demonstrated that lower omega-3 PUFA levels in the peripheral blood are associated with an increased risk of developing IFN- $\alpha$-induced depression over the following weeks. ${ }^{13)}$ Taking together, we conducted a 2-week, double-blind, placebo-controlled trial, to test the differential effects of the omega-3 PUFAs in the prevention of IFN- $\alpha$ induced depression.

Two hundred and seven patients with HCV were screened, 162 of them consented to participate and were randomized to the study to receive EPA, DHA or placebo, and all of them completed the two-week trial; 152 participants were followed throughout the 24 weeks of IFN- $\alpha$ treatment, and were included in the analysis. Compared with placebo, the incident rates of IFN- $\alpha$-induced depression were significantly lower in EPA-, but not in DHA-treated patients (rates: $10 \%$ and $28 \%$, respectively, vs. $30 \%$ for placebo). Both EPA and DHA pre-treatment significantly delayed the onset of IFN-induced depression (average weeks of onset: 12.0 and 11.7, respectively, vs. 5.3 for placebo). EPA and DHA were both well tolerated in this population. The study shows that EPA appears to be effective in the prevention of IFN-induced depression and suggests that omega-3 PUFAs are potentially a suitable preventive strategy for a wider pool of patients with depression associated with inflammation. ${ }^{73)}$

\section{Omega-3 PUFAs in Prevention of Anxiety Disorders}

Some preclinical data support omega-3 PUFA as an effective treatment of anxiety disorders. For example, Song et al ${ }^{80,81)}$ found that an EPA-rich diet could reduce the development of anxiety-like behaviors in rat as well as normalizing dopamine levels in the ventral striatum. Regarding therapeutic intervention, Fux et al $^{82)}$ conducted a placebo-controlled cross-over trial of adjunctive EPA treatment in patients with obsessive-compulsive disorder (OCD). Eleven patients with OCD were randomly allocated to begin 6 weeks of placebo followed by 6 weeks of $2 \mathrm{~g} / \mathrm{d}$ of EPA or EPA followed by placebo. Unfortunately they found no benefit of EPA augmentation on symptoms of anxiety, depression and obsessive-compulsiveness. ${ }^{82}$ Similarly, $2 \mathrm{~g} / \mathrm{d}$ of EPA augmentation was ineffective in relieving anger, hostility, or depressive symptoms among seven posttraumatic stress disorder (PTSD) patients in open-label case series. ${ }^{83)}$ These 2 studies are unfortunately limited by small sample sizes.

Buydens-Branchey et al ${ }^{84)}$ conducted a randomizedcontrolled trial and showed the daily administration of
2,250 mg/d of EPA plus $500 \mathrm{mg} / \mathrm{d}$ of DHA for 3 months was accompanied by significant decreases in anger and anxiety scores compared to placebo group in 22 substance abusers. They also showed that these changes were associated with increases in plasma levels of both DHA and EPA but an increase in EPA was more robustly correlated with low end-of-trial anxiety symptom and an increase in DHA was more robustly correlated with low end-of-trial anger symptom. These studies suggested that EPA might be effective in control of anger and anxiety, but more well-designed larger studies focusing on specific condition are needed to clarify the efficacy of omega-3 PUFA.

Haberka et $a l^{85)}$ conducted a randomized non-placebo controlled trial to determine the efficacy of $465 \mathrm{mg} / \mathrm{d}$ EPA plus $375 \mathrm{mg} / \mathrm{d}$ DHA on top of the regular pharmacotherapy in 52 patients with post myocardial infarction. They found that omega-3 PUFA supplementation revealed additional effects on decreasing depressive and anxiety symptoms. In a randomized double-blind controlled trial, Kiecolt-Glaser et al ${ }^{86)}$ firstly showed that omega-3 PUFA supplementation could reduce inflammation and anxiety among healthy young adults who faced stressful major examination. The medical students who received 2,085 $\mathrm{mg} / \mathrm{d}$ of EPA and $348 \mathrm{mg} / \mathrm{d}$ of DHA for 12 weeks showed a $14 \%$ decrease in stress-stimulated interleukin 6 production and a $20 \%$ reduction in anxiety symptoms compared to subjects who received placebo. No significant change in depressive symptoms was shown between the two groups. These studies suggested that EPA rather than DHA might be efficacious in selective prevention of anxiety under serious physical condition or stressful situation.

Despite that many clinical trials testing efficacy of omega-3 PUFA in anxiety disorders have been done, the investigation about preventive intervention is still lacking. Recently, we administered 1,470 mg/d of DHA plus 147 $\mathrm{mg} / \mathrm{d}$ of EPA for 12 weeks in accidentally injured patients to prevent PTSD. We found a beneficial effect of omega-3 PUFAs for minimizing PTSD symptoms compared with the hypothetical means in our previous data. ${ }^{87)}$ In April 2011 when Japan was hit by the Great East Earthquake, we conducted a randomized non-placebo controlled trial in medical rescue workers during the acute distressing phase to determine whether omega-3 PUFA can attenuate PTSD symptoms compared to psycho-education alone. Although there were no significant differences between the two groups, we found the benefit of $1,568 \mathrm{mg} / \mathrm{d}$ of DHA and $157 \mathrm{mg} / \mathrm{d}$ of EPA for attenuating PTSD symptoms in women. ${ }^{88)}$ In addition, we recently reported a result of a randomized double-blind controlled trial to prevent PTSD 
among 110 accidentally injured patients admitted to an intensive care unit. All patients received psycho-education and were randomly assigned to receive $1,470 \mathrm{mg} / \mathrm{d}$ of DHA plus $147 \mathrm{mg} / \mathrm{d}$ EPA or placebo for 12 weeks. Unfortunately we did not find significant differences in PTSD symptoms at 3-month follow-up visits between the two groups (Matsuoka, revision under review).

\section{Biological Mechanisms Underlying Omega-3 PUFAs' Psychotropic Effects}

The brain is highly enriched with omega-3 PUFAs and their derivatives, which regulate several biological processes, such as neurotransmission, cell survival and neuroinflammation, and thereby mood and cognition. The beneficial effects of omega-3 PUFA in preventing depression and anxiety are supported in pre-clinical studies of animal and cellular models. For example, omega-3 PUFAs are associated with a preventive effect of depression-like and anxiety-like behaviors in animal model in rats. ${ }^{66-69)}$ In addition, the level of brain DHA is negatively correlated to the depression-like behaviors, measured by immobility time in the forced-swimming test. ${ }^{67)}$ Although the biological mechanisms underlying the psychotropic effects of omega-3 PUFAs are not fully understood, we summarize a few possible explanations.

\section{The role of omega-3 PUFAs in neurotransmission}

The change in omega-3 PUFA concentrations in the brain, induced by chronic deficiency in dietary omega- 3 PUFAs, could lead to an increase in serotonin $2\left(5-\mathrm{HT}_{2}\right)$ and decrease in dopamine $2\left(\mathrm{D}_{2}\right)$ receptor density in the frontal cortex. ${ }^{89-91)}$ The upregulation of $5-\mathrm{HT}_{2 \mathrm{~A} / \mathrm{C}}$ receptors and downregulation of dopamine receptors are thought to play a role in the pathophysiology of depression. ${ }^{92)}$ In addition, higher cerebrospinal fluid levels of 5-hydroxy-indoleacetic acid (5-HIAA), a metabolite of serotonin and an indicator of brain serotonin turnover, has been shown to be associated with high plasma concentration of omega-3 PUFAs among healthy subjects. ${ }^{25)}$ Biochemical studies have also shown that omega-3 PUFAs increased cerebrospinal fluid 5-HIAA releases, ${ }^{93)}$ which are commonly associated with the improvement of depression and anxiety symptoms.

\section{The role of omega-3 PUFAs in anti-inflammation and anti-oxidation}

The inflammation theory of depression has been supported from several lines of evidence including increasing inflammatory biomarkers in clinical depressed patients and the observed behavioral changes related to inflammatory changes. ${ }^{20)}$ Upon activation, microglia, the resident macrophages of the brain, up-regulate expression of detrimental factors of reactive oxygen species such as nitric oxide via inducible nitric oxide synthase (iNOS) and induce oxidative stress, contributing to neuropsychiatric pathogenesis. $^{70)}$ On the other hand, expression of anti-oxidative enzymes like heme oxygenase-1 (HO-1) can reverse oxidative stress and may characterize antidepressant mechanisms. ${ }^{21)}$ Omega-3 PUFAs are anti-inflammatory and anti-oxidative, and therefore could be beneficial in depression and anxiety. ${ }^{16,20,21)}$

\section{The role of omega-3 PUFAs in neuroplasticity}

Various chronic antidepressants, which are the current standard treatments, increase adult hippocampal neurogenesis, ${ }^{94,95)}$ and animal studies suggest that the behavioral effects of chronic antidepressants may be mediated by an induction of neuroplasticity and neurogenesis in the brain. ${ }^{95)}$ EPA has been shown to increase cortical concentrations of $\mathrm{N}$-acetyl aspartate, a putative marker of neuronal integrity and function, thereby protecting against excitotoxic apoptosis in a small clinical study. ${ }^{47)}$ In addition, pre-clinical studies have shown that omega-3 PUFAs promote hippocampal neurogenesis in adult animals. ${ }^{96,97)}$ Moreover, omega-3 PUFAs may modulate neurotrophins, ${ }^{98-100)}$ which might be a direct mechanism to mediate neurogenesis and antidepressant effects.

\section{SUMMARY}

Nutrition is a modifiable environmental factor that might be important in prevention medicine. Omega-3 PUFAs are well tolerated and accepted, and have been applied for many years as the secondary prevention in various chronic medical diseases and mental disorders. In this review, we found that the clinical evidence about omega-3 PUFAs' preventive benefits on mood and anxiety disorders is supported by their regulatory effects on immunomodulation, anti-inflammation, signal transduction, neurotransmission and neuroprotection. Our current review calls for more prospective clinical trials in identified high-risk populations to justify the preventive application of omega-3 PUFAs in daily practice.

\section{Acknowledgments}

Work included in this review was supported by the following grants: MOST103-2320-B-039-MY3, MOST1032320-B-038-012-MY3, NSC 103-2923-B-039-002-MY3, 
102-2911-I-039-501, 101-2628-B-039-001-MY3 and 1012320-B-038-020-MY2 from the Ministry of Science and Techonology and CMU103-S-03, DMR-103-078, 102-068 and 101-081 from the China Medical University in Taiwan.

\section{REFERENCES}

1. Collins PY, Patel V, Joestl SS, March D, Insel TR, Daar AS, et al. Grand challenges in global mental health. Nature 2011;475:27-30

2. Thornicroft G. Most people with mental illness are not treated. Lancet 2007;370:807-808.

3. Han C, Pae CU. Do we need to consider ethno-cultural variation in the use of atypical antipsychotics for Asian patients with major depressive disorder? CNS Drugs 2013;27 Suppl 1:S47-S51.

4. Cyril S, Oldroyd JC, Renzaho A. Urbanisation, urbanicity, and health: a systematic review of the reliability and validity of urbanicity scales. BMC Public Health 2013;13:513.

5. Gómez-Pinilla F. Brain foods: the effects of nutrients on brain function. Nat Rev Neurosci 2008;9:568-578.

6. Su KP, Wang SM, Pae CU. Omega-3 polyunsaturated fatty acids for major depressive disorder. Expert Opin Investig Drugs 2013;22:1519-1534.

7. van Elst K, Bruining H, Birtoli B, Terreaux C, Buitelaar JK, Kas MJ. Food for thought: dietary changes in essential fatty acid ratios and the increase in autism spectrum disorders. Neurosci Biobehav Rev 2014;45:369-378.

8. Politi P, Rocchetti M, Emanuele E, Rondanelli M, Barale F. Randomized placebo-controlled trials of omega-3 polyunsaturated fatty acids in psychiatric disorders: a review of the current literature. Curr Drug Discov Technol 2013;10: 245-253.

9. Mischoulon D, Freeman MP. Omega-3 fatty acids in psychiatry. Psychiatr Clin North Am 2013;36:15-23.

10. McNamara RK. Long-chain omega-3 fatty acid deficiency in mood disorders: rationale for treatment and prevention. Curr Drug Discov Technol 2013;10:233-244.

11. Su KP, Balanzá-Martínez V. Role of omega-3 fatty acids in mood disorders. In: McNamara RK, editor. The omega-3 fatty acid deficiency syndrome: opportunities for disease prevention. New York:Nova Science Pub Inc.;2013. p.315-336.

12. Lin PY, Chiu CC, Huang SY, Su KP. A meta-analytic review of polyunsaturated fatty acid compositions in dementia. J Clin Psychiatry 2012;73:1245-1254.

13. Su KP, Huang SY, Peng CY, Lai HC, Huang CL, Chen $\mathrm{YC}$, et al. Phospholipase A2 and cyclooxygenase 2 genes influence the risk of interferon-alpha-induced depression by regulating polyunsaturated fatty acids levels. Biol Psychiatry 2010;67:550-557.

14. Lin PY, Huang SY, Su KP. A meta-analytic review of polyunsaturated fatty acid compositions in patients with depression. Biol Psychiatry 2010;68:140-147.

15. Su KP, Huang SY, Chiu TH, Huang KC, Huang CL, Chang $\mathrm{HC}$, et al. Omega-3 fatty acids for major depressive disorder during pregnancy: results from a randomized, doubleblind, placebo-controlled trial. J Clin Psychiatry 2008;69. 644-651.

16. Su KP. Mind-body interface: the role of $n-3$ fatty acids in psychoneuroimmunology, somatic presentation, and medical illness comorbidity of depression. Asia Pac J Clin Nutr 2008;17 Suppl 1:151-157.

17. Lin PY, Su KP. A meta-analytic review of double-blind, placebo-controlled trials of antidepressant efficacy of omega-3 fatty acids. J Clin Psychiatry 2007;68:1056-1061.

18. Su KP. Biological mechanism of antidepressant effect of omega-3 fatty acids: how does fish oil act as a 'mind-body interface'? Neurosignals 2009;17:144-152.

19. Bailey RL, Gahche JJ, Miller PE, Thomas PR, Dwyer JT, Why US adults use dietary supplements. JAMA Intern Med 2013;173:355-361.

20. Su KP. Inflammation in psychopathology of depression: clinical, biological, and therapeutic implications. BioMedicine 2012;2:68-74.

21. Lu DY, Tsao YY, Leung YM, Su KP. Docosahexaenoic acid suppresses neuroinflammatory responses and induces heme oxygenase-1 expression in BV-2 microglia: implications of antidepressant effects for $\omega-3$ fatty acids. Neuropsychopharmacology 2010;35:2238-2248.

22. Solis M. Prevention: Before the break. Nature 2014;508: S12-S13.

23. Kris-Etherton PM, Harris WS, Appel LJ; American Heart Association, Nutrition Committee. Fish consumption, fish oil, omega-3 fatty acids, and cardiovascular disease. Circulation 2002;106:2747-2757.

24. Maes M, Leonard B, Fernandez A, Kubera M, Nowak G, Veerhuis R, et al. (Neuro)inflammation and neuroprogression as new pathways and drug targets in depression: from antioxidants to kinase inhibitors. Prog Neuropsychopharmacol Biol Psychiatry 2011;35:659-663.

25. Hibbeln JR. Fish consumption and major depression. Lancet 1998;351:1213.

26. Hibbeln JR, Nieminen LR, Blasbalg TL, Riggs JA, Lands WE. Healthy intakes of $n-3$ and $n-6$ fatty acids: estimations considering worldwide diversity. Am J Clin Nutr 2006;83(6 Suppl):1483S-1493S.

27. Noaghiul S, Hibbeln JR. Cross-national comparisons of seafood consumption and rates of bipolar disorders. Am J Psychiatry 2003;160:2222-2227.

28. McNamara RK, Hahn CG, Jandacek R, Rider T, Tso P, Stanford KE, et al. Selective deficits in the omega-3 fatty acid docosahexaenoic acid in the postmortem orbitofrontal cortex of patients with major depressive disorder. Biol Psychiatry 2007;62:17-24.

29. Hamazaki K, Hamazaki T, Inadera H. Abnormalities in the fatty acid composition of the postmortem entorhinal cortex of patients with schizophrenia, bipolar disorder, and major depressive disorder. Psychiatry Res 2013;210:346-350.

30. Hamazaki K, Hamazaki T, Inadera H. Fatty acid composition in the postmortem amygdala of patients with schizophrenia, bipolar disorder, and major depressive disorder. $J$ Psychiatr Res 2012;46:1024-1028.

31. De Vriese SR, Christophe AB, Maes M. Lowered serum n-3 polyunsaturated fatty acid (PUFA) levels predict the occurrence of postpartum depression: further evidence that lowered n-PUFAs are related to major depression. Life Sci 2003; 73:3181-3187.

32. Green P, Hermesh H, Monselise A, Marom S, Presburger G, Weizman A. Red cell membrane omega-3 fatty acids are decreased in nondepressed patients with social anxiety disorder. Eur Neuropsychopharmacol 2006;16:107-113.

33. Tiemeier H, van Tuijl HR, Hofman A, Kiliaan AJ, Breteler MM. Plasma fatty acid composition and depression are associated in the elderly: the Rotterdam Study. Am J Clin Nutr 2003;78:40-46.

34. Frasure-Smith N, Lespérance F, Julien P. Major depression is associated with lower omega-3 fatty acid levels in patients with recent acute coronary syndromes. Biol Psychiatry 
2004; 55:891-896.

35. Chiu CC, Huang SY, Su KP, Lu ML, Huang MC, Chen $\mathrm{CC}$, et al. Polyunsaturated fatty acid deficit in patients with bipolar mania. Eur Neuropsychopharmacol 2003;13:99-103.

36. McNamara RK, Jandacek R, Rider T, Tso P, Dwivedi Y, Pandey GN. Selective deficits in erythrocyte docosahexaenoic acid composition in adult patients with bipolar disorder and major depressive disorder. J Affect Disord 2010;126:303-311.

37. Ranjekar PK, Hinge A, Hegde MV, Ghate M, Kale A, Sitasawad S, et al. Decreased antioxidant enzymes and membrane essential polyunsaturated fatty acids in schizophrenic and bipolar mood disorder patients. Psychiatry Res 2003;121:109-122.

38. Sublette ME, Bosetti F, DeMar JC, Ma K, Bell JM, Fagin-Jones S, et al. Plasma free polyunsaturated fatty acid levels are associated with symptom severity in acute mania. Bipolar Disord 2007;9:759-765.

39. Clayton EH, Hanstock TL, Hirneth SJ, Kable CJ, Garg ML, Hazell PL. Long-chain omega-3 polyunsaturated fatty acids in the blood of children and adolescents with juvenile bipolar disorder. Lipids 2008;43:1031-1038.

40. Sobczak S, Honig A, Christophe A, Maes M, Helsdingen $\mathrm{RW}$, De Vriese SA, et al. Lower high-density lipoprotein cholesterol and increased omega- 6 polyunsaturated fatty acids in first-degree relatives of bipolar patients. Psychol Med 2004;34:103-112.

41. Stoll AL, Severus WE, Freeman MP, Rueter S, Zboyan HA, Diamond E, et al. Omega 3 fatty acids in bipolar disorder: a preliminary double-blind, placebo-controlled trial. Arch Gen Psychiatry 1999;56:407-412.

42. Su KP, Shen WW, Huang SY. Are omega3 fatty acids beneficial in depression but not mania? Arch Gen Psychiatry 2000;57:716-717.

43. Osher Y, Bersudsky Y, Belmaker RH. Omega-3 eicosapentaenoic acid in bipolar depression: report of a small open-label study. J Clin Psychiatry 2005;66:726-729.

44. Sagduyu K, Dokucu ME, Eddy BA, Craigen G, Baldassano CF, Yildiz A. Omega-3 fatty acids decreased irritability of patients with bipolar disorder in an add-on, open label study. Nutr J 2005;4:6.

45. Frangou S, Lewis M, McCrone P. Efficacy of ethyl-eicosapentaenoic acid in bipolar depression: randomised doubleblind placebo-controlled study. Br J Psychiatry 2006;188: 46-50.

46. Clayton EH, Hanstock TL, Hirneth SJ, Kable CJ, Garg ML, Hazell PL. Reduced mania and depression in juvenile bipolar disorder associated with long-chain omega-3 polyunsaturated fatty acid supplementation. Eur J Clin Nutr 2009;63:1037-1040.

47. Frangou S, Lewis M, Wollard J, Simmons A. Preliminary in vivo evidence of increased $N$-acetyl-aspartate following eicosapentanoic acid treatment in patients with bipolar disorder. J Psychopharmacol 2007;21:435-439.

48. Keck PE Jr, Mintz J, McElroy SL, Freeman MP, Suppes T, Frye MA, et al. Double-blind, randomized, placebocontrolled trials of ethyl-eicosapentanoate in the treatment of bipolar depression and rapid cycling bipolar disorder. Biol Psychiatry 2006;60:1020-1022.

49. Gracious BL, Chirieac MC, Costescu S, Finucane TL, Youngstrom EA, Hibbeln JR. Randomized, placebocontrolled trial of flax oil in pediatric bipolar disorder. Bipolar Disord 2010;12:142-154.

50. Freeman MP, Mischoulon D, Tedeschini E, Goodness T, Cohen LS, Fava M, et al. Complementary and alternative medicine for major depressive disorder: a meta-analysis of patient characteristics, placebo-response rates, and treatment outcomes relative to standard antidepressants. J Clin Psychiatry 2010;71:682-688.

51. Sublette ME, Ellis SP, Geant AL, Mann JJ. Meta-analysis of the effects of eicosapentaenoic acid (EPA) in clinical trials in depression. J Clin Psychiatry 2011;72:1577-1584.

52. Martins JG, Bentsen H, Puri BK. Eicosapentaenoic acid appears to be the key omega-3 fatty acid component associated with efficacy in major depressive disorder: a critique of Bloch and Hannestad and updated metaanalysis. Mol Psychiatry 2012;17:1144-1149.

53. Lin PY, Mischoulon D, Freeman MP, Matsuoka Y, Hibbeln J, Belmaker RH, et al. Are omega-3 fatty acids antidepressants or just mood-improving agents? The effect depends upon diagnosis, supplement preparation, and severity of depression. Mol Psychiatry 2012;17:1161-1163.

54. Mischoulon D, Papakostas GI, Dording CM, Farabaugh $\mathrm{AH}$, Sonawalla SB, Agoston AM, et al. A double-blind, randomized controlled trial of ethyl-eicosapentaenoate for major depressive disorder. J Clin Psychiatry 2009;70: 1636-1644.

55. Mischoulon D, Best-Popescu C, Laposata M, Merens W, Murakami JL, Wu SL, et al. A double-blind dose-finding pilot study of docosahexaenoic acid (DHA) for major depressive disorder. Eur Neuropsychopharmacol 2008;18: 639-645.

56. Nemets H, Nemets B, Apter A, Bracha Z, Belmaker RH. Omega-3 treatment of childhood depression: a controlled, double-blind pilot study. Am J Psychiatry 2006;163:10981100.

57. Peet M, Horrobin DF. A dose-ranging study of the effects of ethyl-eicosapentaenoate in patients with ongoing depression despite apparently adequate treatment with standard drugs. Arch Gen Psychiatry 2002;59:913-919.

58. Nemets B, Stahl Z, Belmaker RH. Addition of omega-3 fatty acid to maintenance medication treatment for recurrent unipolar depressive disorder. Am J Psychiatry 2002; 159:477-479.

59. Su KP, Huang SY, Chiu CC, Shen WW. Omega-3 fatty acids in major depressive disorder. A preliminary doubleblind, placebo-controlled trial. Eur Neuropsychopharmacol 2003; 13:267-271.

60. Sinn N, Milte CM, Street SJ, Buckley JD, Coates AM, Petkov J, et al. Effects of $n-3$ fatty acids, EPA v. DHA, on depressive symptoms, quality of life, memory and executive function in older adults with mild cognitive impairment: a 6-month randomised controlled trial. Br J Nutr 2012; 107:1682-1693.

61. Jazayeri S, Tehrani-Doost M, Keshavarz SA, Hosseini M, Djazayery A, Amini H, et al. Comparison of therapeutic effects of omega-3 fatty acid eicosapentaenoic acid and fluoxetine, separately and in combination, in major depressive disorder. Aust N Z J Psychiatry 2008;42:192-198.

62. Appleton KM, Rogers PJ, Ness AR. Updated systematic review and meta-analysis of the effects of n-3 long-chain polyunsaturated fatty acids on depressed mood. Am J Clin Nutr 2010;91:757-770.

63. Rogers PJ, Appleton KM, Kessler D, Peters TJ, Gunnell $\mathrm{D}$, Hayward RC, et al. No effect of n-3 long-chain polyunsaturated fatty acid (EPA and DHA) supplementation on depressed mood and cognitive function: a randomised controlled trial. Br J Nutr 2008;99:421-431.

64. Bloch MH, Hannestad J. Omega-3 fatty acids for the treatment of depression: systematic review and meta-analysis. 
Mol Psychiatry 2012;17:1272-1282.

65. Richardson AJ. n-3 Fatty acids and mood: the devil is in the detail. Br J Nutr 2008;99:221-223.

66. Carlezon WA Jr, Mague SD, Parow AM, Stoll AL, Cohen $\mathrm{BM}$, Renshaw PF. Antidepressant-like effects of uridine and omega-3 fatty acids are potentiated by combined treatment in rats. Biol Psychiatry 2005;57:343-350.

67. Huang SY, Yang HT, Chiu CC, Pariante CM, Su KP. Omega-3 fatty acids on the forced-swimming test. J Psychiatr Res 2008;42:58-63.

68. Song C, Zhang XY, Manku M. Increased phospholipase A2 activity and inflammatory response but decreased nerve growth factor expression in the olfactory bulbectomized rat model of depression: effects of chronic ethyl-eicosapentaenoate treatment. J Neurosci 2009;29:14-22.

69. Lakhwani L, Tongia SK, Pal VS, Agrawal RP, Nyati P, Phadnis P. Omega-3 fatty acids have antidepressant activity in forced swimming test in Wistar rats. Acta Pol Pharm 2007;64:271-276.

70. Lu DY, Leung YM, Su KP. Interferon- $\alpha$ induces nitric oxide synthase expression and haem oxygenase-1 downregulation in microglia: implications of cellular mechanism of IFN- $\alpha$-induced depression. Int $J$ Neuropsychopharmacol 2013;16:433-444.

71. Berton O, Nestler EJ. New approaches to antidepressant drug discovery: beyond monoamines. Nat Rev Neurosci 2006; 7:137-151.

72. Fournier JC, DeRubeis RJ, Hollon SD, Dimidjian S, Amsterdam JD, Shelton RC, et al. Antidepressant drug effects and depression severity: a patient-level meta-analysis. JAMA 2010;303:47-53.

73. Su KP, Lai HC, Yang HT, Su WP, Peng CY, Chang JP, et al. Omega-3 fatty acids in the prevention of interferonalpha-induced depression: results from a randomized, controlled trial. Biol Psychiatry 2014;76:559-566.

74. Dalton SO, Johansen C, Mellemkjaer L, Nørgård B, Sørensen HT, Olsen JH. Use of selective serotonin reuptake inhibitors and risk of upper gastrointestinal tract bleeding: a population-based cohort study. Arch Intern Med 2003;163:59-64.

75. Gleason OC, Yates WR, Philipsen MA, Isbell MD, Pollock BG. Plasma levels of citalopram in depressed patients with hepatitis C. Psychosomatics 2004;45:29-33.

76. Hejny C, Sternberg P, Lawson DH, Greiner K, Aaberg TM Jr. Retinopathy associated with high-dose interferon alfa- $2 b$ therapy. Am J Ophthalmol 2001;131:782-787.

77. Musselman DL, Lawson DH, Gumnick JF, Manatunga AK, Penna S, Goodkin RS, et al. Paroxetine for the prevention of depression induced by high-dose interferon alfa. $N$ Engl J Med 2001;344:961-966.

78. Morasco BJ, Rifai MA, Loftis JM, Indest DW, Moles JK, Hauser P. A randomized trial of paroxetine to prevent interferon-alpha-induced depression in patients with hepatitis C. J Affect Disord 2007;103:83-90.

79. Wu PL, Liao KF, Peng CY, Pariante CM, Su KP. Manic episode associated with citalopram therapy for interferoninduced depression in a patient with chronic hepatitis $C$ infection. Gen Hosp Psychiatry 2007;29:374-376.

80. Song C, Li X, Kang Z, Kadotomi Y. Omega-3 fatty acid ethyl-eicosapentaenoate attenuates IL-1beta-induced changes in dopamine and metabolites in the shell of the nucleus accumbens: involved with PLA2 activity and corticosterone secretion. Neuropsychopharmacology 2007;32:736-744.

81. Song C, Li X, Leonard BE, Horrobin DF. Effects of dietary n-3 or n-6 fatty acids on interleukin-1beta-induced anxiety, stress, and inflammatory responses in rats. J Lipid Res 2003;44:1984-1991.

82. Fux M, Benjamin J, Nemets B. A placebo-controlled cross-over trial of adjunctive EPA in OCD. J Psychiatr Res 2004;38:323-325.

83. Zeev K, Michael M, Ram K, Hagit C. Possible deleterious effects of adjunctive omega-3 fatty acids in post-traumatic stress disorder patients. Neuropsychiatr Dis Treat 2005; 1:187-190.

84. Buydens-Branchey L, Branchey M, Hibbeln JR. Associations between increases in plasma $n-3$ polyunsaturated fatty acids following supplementation and decreases in anger and anxiety in substance abusers. Prog Neuropsychopharmacol Biol Psychiatry 2008;32:568-575.

85. Haberka M, Mizia-Stec K, Mizia M, Gieszczyk K, Chmiel A, Sitnik-Warchulska K, et al. Effects of $n-3$ polyunsaturated fatty acids on depressive symptoms, anxiety and emotional state in patients with acute myocardial infarction. Pharmacol Rep 2013;65:59-68.

86. Kiecolt-Glaser JK, Belury MA, Andridge R, Malarkey WB, Glaser R. Omega-3 supplementation lowers inflammation and anxiety in medical students: a randomized controlled trial. Brain Behav Immun 2011;25:1725-1734.

87. Matsuoka Y, Nishi D, Yonemoto N, Hamazaki K, Hashimoto K, Hamazaki T. Omega-3 fatty acids for secondary prevention of posttraumatic stress disorder after accidental injury: an open-label pilot study. J Clin Psychopharmacol 2010;30:217-219.

88. Nishi D, Koido $Y$, Nakaya $N$, Sone $T$, Noguchi $H$, Hamazaki K, et al. Fish oil for attenuating posttraumatic stress symptoms among rescue workers after the great east Japan earthquake: a randomized controlled trial. Psychother Psychosom 2012;81:315-317.

89. Delion S, Chalon S, Hérault J, Guilloteau D, Besnard JC, Durand G. Chronic dietary alpha-linolenic acid deficiency alters dopaminergic and serotoninergic neurotransmission in rats. J Nutr 1994;124:2466-2476.

90. Chalon S, Vancassel S, Zimmer L, Guilloteau D, Durand G. Polyunsaturated fatty acids and cerebral function: focus on monoaminergic neurotransmission. Lipids 2001;36: 937-944.

91. Berg KA, Maayani S, Clarke WP. 5-hydroxytryptamine2C receptor activation inhibits 5-hydroxytryptaminelB-like receptor function via arachidonic acid metabolism. Mol Pharmacol 1996;50:1017-1023.

92. Maes M, Meltzer HYM. The serotonin hypothesis of major depression. In: Bloom FE, Kupfer DJ, editors. Psychopharmacology, the Fourth Generation of Progress. New York:Raven Press;1995. p.933-941.

93. Nizzo MC, Tegos S, Gallamini A, Toffano G, Polleri A, Massarotti M. Brain cortex phospholipids liposomes effects on CSF HVA, 5-HIAA and on prolactin and somatotropin secretion in man. J Neural Transm 1978;43:93-102.

94. Duman RS, Malberg J, Thome J. Neural plasticity to stress and antidepressant treatment. Biol Psychiatry 1999;46: 1181-1191.

95. Santarelli L, Saxe M, Gross C, Surget A, Battaglia F, Dulawa S, et al. Requirement of hippocampal neurogenesis for the behavioral effects of antidepressants. Science 2003:301:805-809.

96. Beltz BS, Tlusty MF, Benton JL, Sandeman DC. Omega-3 fatty acids upregulate adult neurogenesis. Neurosci Lett 2007:415:154-158.

97. Kawakita E, Hashimoto M, Shido O. Docosahexaenoic acid promotes neurogenesis in vitro and in vivo. 
Neuroscience 2006;139:991-997.

98. Blondeau N, Nguemeni C, Debruyne DN, Piens M, Wu X, Pan H, et al. Subchronic alpha-linolenic acid treatment enhances brain plasticity and exerts an antidepressant effect: a versatile potential therapy for stroke. Neuropsychopharmacology 2009;34:2548-2559.

99. Venna VR, Deplanque D, Allet C, Belarbi K, Hamdane M,
Bordet R. PUFA induce antidepressant-like effects in parallel to structural and molecular changes in the hippocampus. Psychoneuroendocrinology 2009;34:199-211.

100. Wu A, Ying Z, Gomez-Pinilla F. Dietary omega-3 fatty acids normalize BDNF levels, reduce oxidative damage, and counteract learning disability after traumatic brain injury in rats. J Neurotrauma 2004;21:1457-1467. 